\title{
Clinical value of CagA, c-Met, PI3K and Beclin-1 expressed in gastric cancer and their association with prognosis
}

\author{
XIAOJUN HUANG ${ }^{1,2^{*}}$, CHAOQUN WANG $^{1,3^{*}}$, JINMIN SUN $^{3}$, JUN LUO $^{1}$, \\ JIANGZHOU YOU $^{1}$, LINCHUAN LIAO ${ }^{1}$ and MINGYUAN LI ${ }^{1}$
}

\begin{abstract}
${ }^{1}$ Department of Microbiology, West China School of Preclinical and Forensic Medicine, Sichuan University, Chengdu, Sichuan 610041; ${ }^{2}$ Department of Pathogenic Biology and Immunology, School of Medicine, Hubei University for Nationalities, Enshi, Hubei 445000; ${ }^{3}$ Department of Pathology, Xuzhou Medical College, Xuzhou, Jiangsu 221004, P.R. China
\end{abstract}

Received December 12, 2015; Accepted May 11, 2017

DOI: $10.3892 / \mathrm{ol} .2017 .7394$

\begin{abstract}
Gastric cancer (GC) is the fourth most common type of malignant tumor worldwide, and causes the second highest number of cancer-associated mortalities in 2012. Gastric tumorigenesis is a multistep and multifactorial process. In the present study, tissue microarray and immunohistochemistry analysis were used to detect cytotoxin-associated gene A (CagA), c-Met, phosphatidylinositol-4,5-bisphosphate 3-kinase (PI3K) and Beclin-1 expression in 121 GC tumors and 120 normal gastric tissues. The clinical relevance and prognostic implications of CagA, c-Met, PI3K and Beclin-1 expression in GC patients were analyzed. Furthermore, the Cox proportional hazards model was performed to indicate the independent prognostic factors for GC patients, including various clinicopathological parameters and CagA, c-Met, PI3K and Beclin-1 expression. The results indicated that CagA-positive H. pylori infection, c-Met, PI3K and Beclin-1 may have major roles in the oncogenesis, invasion and lymph node metastasis of GC. The disease-free survival rate was negatively associated with the expression of c-Met and CagA in tissues, and was positively associated with Beclin-1 expression. Overall survival was also negatively associated with the expression of c-Met and PI3K, and was positively associated with Beclin-1 expression. This indicated that c-Met and Beclin-1 may be independent and efficient biomarkers for predicting the DFS of patients with GC. Furthermore, in CagA-positive H. pylori infection-associated GC, c-Met expression was significantly upregulated and Beclin-1 expression was significantly downregulated. CagA-positive H. pylori infection therefore associated with the c-Met
\end{abstract}

Correspondence to: Professor Mingyuan Li, Department of Microbiology, West China School of Preclinical and Forensic Medicine, Sichuan University, 17 People's South Road, Chengdu, Sichuan 610041, P.R. China

E-mail:1my3985@sina.com

*Contributed equally

Key words: gastric cancer, CagA, c-Met, PI3K, Beclin-1, prognosis signaling pathway and the suppression of autophagy in the neoplasia, invasion and metastasis of GC.

\section{Introduction}

In February 2014, the World Health Organization (WHO) released the 2014 World Cancer Report (1). The report included the estimation that in 2012, there were 14 million new cases of cancer and 8.2 million cancer-associated mortalities worldwide, of which 21.9 and $26.8 \%$, respectively, occurred in China. Gastric cancer (GC) is the fourth most common type of malignant tumor worldwide and causes the second largest number of mortalities (2). Every year, $\sim 1$ million individuals are diagnosed with GC, including $\sim 42 \%$ of patients with cancer in China (3). According to the WHO data, there were 404,996 newly diagnosed patients with GC in China in 2012. The number of relatively young patients with GC is gradually increasing (3). According to clinical and epidemiological studies, the incidence of GC is as high as 6-11\% among 35-year-olds, as much as three times higher than rates reported in other countries (3). GC-associated mortality rates appear to be trending downwards; however, the GC 5-year survival rate is $30-57.1 \%$ in China, causing $\sim 300,000$ lives to be lost every year $(2,4,5)$.

Gastric tumorigenesis is a multistep and multifactorial process involving genetic, regional, environmental and dietary factors. The International Agency for Research on Cancer confirmed that Helicobacter pylori infection was the most significant risk factor for GC in 2012 (6). H. pylori-mediated GC progression is dependent on the bacterial components expressed, including urease enzymes, adhesins, cytotoxin-associated gene A ( CagA) and vacuolating cytotoxin A. CagA-positive H.pylori strains contain a functional type IV secretion system (TFSS) to facilitate the transfer of bacterial products into host cells (7). Inside the host cell, CagA localizes to the inner surface of the plasma membrane, disrupts cell-cell junctions and undergoes tyrosine phosphorylation interactions from a number of host proteins $(8,9)$. CagA is the only identified protein to be delivered through the TFSS into epithelial cells (5). Previous studies have demonstrated that individuals infected with CagA-positive H.pylori strains present increased inflammation and have a higher risk of developing peptic ulcer disease and GC (10-12). 
The receptor for hepatocyte growth factor/scatter factor, c-Met, is a receptor tyrosine kinase with a well-documented participation in cell invasion (13-16). H. pylori induces an invasive phenotype in gastric epithelial cells through a mechanism that requires the TFSS and the phosphorylation of c-Met. Churin et al (17) reported that c-Met was phosphorylated in response to co-culture with CagA-positive H. pylori; however, the study did not elucidate the mechanism for c-Met activation. The phosphorylation of c-Met can activate the phosphatidylinositol-4,5-bisphosphate 3-kinase (PI3K)/Akt serine/threonine kinase signaling pathway, which suppress autophagy, and promotes tumor cell invasion and the expression of oncogenes. Akt-mediated regulation of autophagy and tumorigenesis is achieved through Beclin-1 phosphorylation (18). Previous studies have suggested that the c-Met/PI3K signaling pathway is particularly active in tumors of the salivary glands, osteosarcoma, ovarian cancer and cervical cancer (19-22). Whether the c-Met/PI3K signaling pathway and the associated suppression of autophagy are involved in CagA-positive H. pylori infection-associated GC has yet to be established.

In the present study, a systematic immunohistochemical analysis of CagA, c-Met, PI3K and Beclin-1 expression in GC tissues was performed. Subsequently, the association between c-Met, PI3K and Beclin-1 expression with clinicopathological factors and CagA-positive H. pylori infection-associated GC was assessed. Disease-free survival (DFS) and overall survival (OS) time data were analyzed to describe the prognostic implications of c-Met, PI3K, Beclin-1 and CagA expression.

\section{Materials and methods}

Tissue specimens. A total of 121 patients with GC were included in the study, including 71 males and 50 females; the patients were aged 34-79 years, with a mean age of 61 years. An additional 120 healthy individuals, to provide normal tissue controls acquired by gastroscopy, were enrolled in the present study. The healthy individuals included 60 male and 60 female volunteers aged between 30 and 66 years. The $\mathrm{GC}$ tissue specimens ( $\geq 5 \mathrm{~cm}$ from the tumor tissue) were collected from resective surgery in the Affiliated Hospital of Xuzhou Medical College (Xuzhou, China) from June 2008 to June 2010. Tissue specimens were formalin-fixed and paraffin-embedded. Patients who had received preoperative chemotherapy, radiotherapy or other treatments were excluded from inclusion in the study, as were those with a family history of GC, or associated inflammatory disease.

Allspecimens werepathologically verified by the Department of Pathology at Xuzhou Medical College. Tumor staging was classified according to the American Joint Committee on Cancer GC TNM staging system (7th edition) (23). DFS was defined as the period between surgery and the day that GC recurrence was first detected. When there was no detected recurrence, the date of patient mortality or last follow-up was used. OS was defined as the period between surgery and the date of patient mortality. The total follow-up period was 5 years after the surgery for the primary lesion. Data including gender, age, histological grade and stage were retrieved from surgical and pathological records.
Informed consent was obtained from all individuals enrolled in the study, and the Xuzhou Medical College Ethics Committee provided ethical approval for the study.

Tissue microarray and immunohistochemistry. The formalin-fixed, paraffin-embedded $4 \mu \mathrm{m}$-thick tissue samples were deparaffinized in xylene (twice for $10 \mathrm{~min}$ ), rehydrated in a graded series of ethanol $(100,95,90,80$ and $75 \%$ for $5 \mathrm{~min}$ each) and rinsed with tap water.

To produce a tissue microarray, hematoxylin and eosin staining was performed to differentiate carcinoma tissue from the surrounding tissue. A total of 3 sites, which were considered typical cancerous gland tissues, were selected by two pathologists of Xuzhou Medical College (Xuzhou, China) from each sample for inclusion in the tissue microarray. The tissue microarray preparation instrument was the MiniCore Tissue Arrayer (ALPHELYS, Plaisir, France), which was used with a $1.0 \mathrm{~mm}$ sampling needle diameter and $2.0 \mathrm{~mm}$ core spacing in a 10x7 organization of 70 sites, in each of 9 tissue chip wax blocks. Each tissue array block was incubated at $52^{\circ} \mathrm{C}$ to integrate for $2 \mathrm{~h}$, then stored at $4^{\circ} \mathrm{C}$ until later use.

Immunohistochemical studies for CagA, c-Met, PI3K and Beclin-1 were performed on $4 \mu \mathrm{m}$-thick tissue sections by machine (Roche Benchmark XT) using the streptavidin-peroxidase method. Antigen retrieval was performed in a microwave at $\mathrm{pH} 6$ for $3 \mathrm{~min}$ at $80^{\circ} \mathrm{C}$ and $3 \mathrm{~min}$ at $50^{\circ} \mathrm{C}$. The activity of endogenous peroxidases was blocked through incubation with $3 \%$ hydrogen peroxidase at room temperature for $20 \mathrm{~min}$. Primary antibodies, consisting of rabbit monoclonal antibodies against CagA (dilution, 1:50; cat. no., sc-25766; Santa Cruz Biotechnology, Inc., Dallas, TX, USA), c-Met (dilution, 1:100; cat. no., ab51067; Abcam, Shanghai, China), PI3K (dilution, 1:25; cat. no., ab86714; Abcam) and Beclin-1 (dilution, 1:100; cat. no., ab55878; Abcam), were incubated with the tissue sections at $4^{\circ} \mathrm{C}$ overnight. Incubation with the alkaline phosphatase-conjugated goat anti-rabbit IgG secondary antibody (dilution, 1:500; cat. no. ZB-2308; ZSGB-BIO Technology, CO., Ltd., Beijing, China) was performed for $15 \mathrm{~min}$ at $37^{\circ} \mathrm{C}$. The sections were developed with 3,3'-diaminobenzidine solution (Maxim Biotech, Inc., Rockville, MD, USA) for 2 min at room temperature and counterstained with hematoxylin. The tissues were then rinsed with PBS for $5 \mathrm{~min}$ and differentiated with $0.1 \% \mathrm{HCl}$ in alcohol at room temperature for $10 \mathrm{sec}$. Finally, the sections were dehydrated, cleared and mounted.

Immunohistochemical scoring. Sections were observed with a light microscope at x200 magnification (DM2500; Leica Biosystems, Wetzlar, Germany) and representative images were captured. Immunostaining was classified according to its location (membrane, cytoplasm or nucleus). Immunoreactivity for CagA, c-Met, PI3K or Beclin-1 were defined by the presence of yellow cytoplasm staining. No evaluation of staining intensity was used in the present study; only the percentage of tumor cells was assessed (0-100\%) for each sample, by counting the frequency of stained cells in five high-power fields (magnification, $x 400$ ), each containing $\sim 100$ cells. The percentage of immunoreactive tumor cells was scored on a scale of 0-4: 0 , no staining; $1+, 1-10 \% ; 2+, 11-30 \% ; 3+, 31-50 \% ; 4+, \geq 50 \%$ ). The expression levels for each protein were divided into two groups, according to score: Low $(1+, 2+)$ and high $(3+, 4+)$. 
Table I. Expression of c-Met, PI3K, Beclin-1 and CagA in gastric cancer and normal gastric mucosa tissues.

\begin{tabular}{|c|c|c|c|c|c|c|c|c|c|}
\hline \multirow[b]{2}{*}{ Tissue type } & \multirow[b]{2}{*}{ Cases, $\mathrm{n}$} & \multicolumn{2}{|c|}{ c-Met } & \multicolumn{2}{|c|}{ PI3K } & \multicolumn{2}{|c|}{ Beclin-1 } & \multicolumn{2}{|c|}{ CagA } \\
\hline & & $\mathrm{n}(\%)$ & P-value ${ }^{a}$ & $\mathrm{n}(\%)$ & P-value & $\mathrm{n}(\%)$ & P-value ${ }^{a}$ & $\mathrm{n}(\%)$ & P-value ${ }^{a}$ \\
\hline Tumor & 121 & $82(67.8)$ & $<0.001$ & $90(74.4)$ & $<0.001$ & $53(43.8)$ & 0.001 & $86(71.1)$ & $<0.001$ \\
\hline Normal & 120 & 20 (16.7) & & $32(26.7)$ & & $96(80.0)$ & & $54(45.0)$ & \\
\hline
\end{tabular}

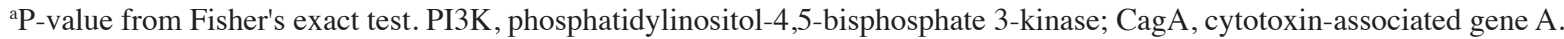

The slides were assessed independently by two pathologists who were blinded to the clinical and outcome data. In the case of divergent results, the two pathologists worked together to review the slides until a consensus was reached.

Statistical analysis. Statistical analysis was performed with SPSS 19.0 software (IBM Corp., Armonk, NY, USA). The association between the expression of CagA, c-Met, PI3K and Beclin-1 with the clinicopathological variables of patients was analyzed by Pearson's $\chi^{2}$ test or Fisher's exact test. The Kaplan-Meier method was used to estimate the DFS and OS rate. Differences in DFS and OS rate were analyzed with the log-rank test. OS and DFS time were analyzed with the Cox proportional hazards model, including hazard ratios (HRs) between prognostic groups, and the associated $95 \%$ confidence intervals (CIs). Correlation between CagA expression with the expression of c-Met, PI3K and Beclin-1 were analyzed by Spearman's rank correlation coefficient $\left(R_{s}\right)$. $\mathrm{P}<0.05$ was considered to indicate a statistically significant difference.

\section{Results}

C-Met, PI3K, Beclin-1 and CagA expression in normal gastric mucosae and $G C$ tissues. In general, absent or weak staining of c-Met was indicated in the gastric mucosa of the 120 non-tumor control samples, compared with relatively high immunoreactivity in the $121 \mathrm{GC}$ samples. A total of 82 of the 121 GC samples (67.8\%) exhibited positive c-Met expression, including 21 with high expression $(4+, 7 ; 3+, 14)$ and 61 with low expression $(2+, 28 ; 1+, 33)$, whereas there were 20 positive samples in non-tumor controls, including 11 with low expression $(2+, 6 ; 1+, 5)$ and 9 with high expression $(4+, 4 ; 3+, 5$; 16.7\%; $\mathrm{P}<0.001$; Table I; Fig. 1A and B).

Similar to c-Met, PI3K expression was generally absent or extremely weak in normal gastric mucosae and relatively high in GC tissue. PI3K expression was identified in 90 of $121 \mathrm{GC}$ samples (74.4\%) and 32 of 120 normal samples (26.7\%). High levels of PI3K expression were detected in 29 cases of GC $(24.0 \% ; 4+, 12 ; 3+, 17)$ and low levels in 61 cases $(2+, 23$; 1+, 38; P<0.001; Table I; Fig. 1C and D). High levels of PI3K expression were detected in 20 cases of normal samples $(62.5 \% ; 4+, 8 ; 3+, 12)$ and low levels were observed in 12 cases $(2+, 7 ; 1+, 5)$.

Compared with normal mucosa tissues (96/120, 80\%), of which 45 exhibited a high level of Beclin-1 expression $(4+, 19$; $3+, 26)$ and 51 demonstrated a low level of Beclin-1 expression
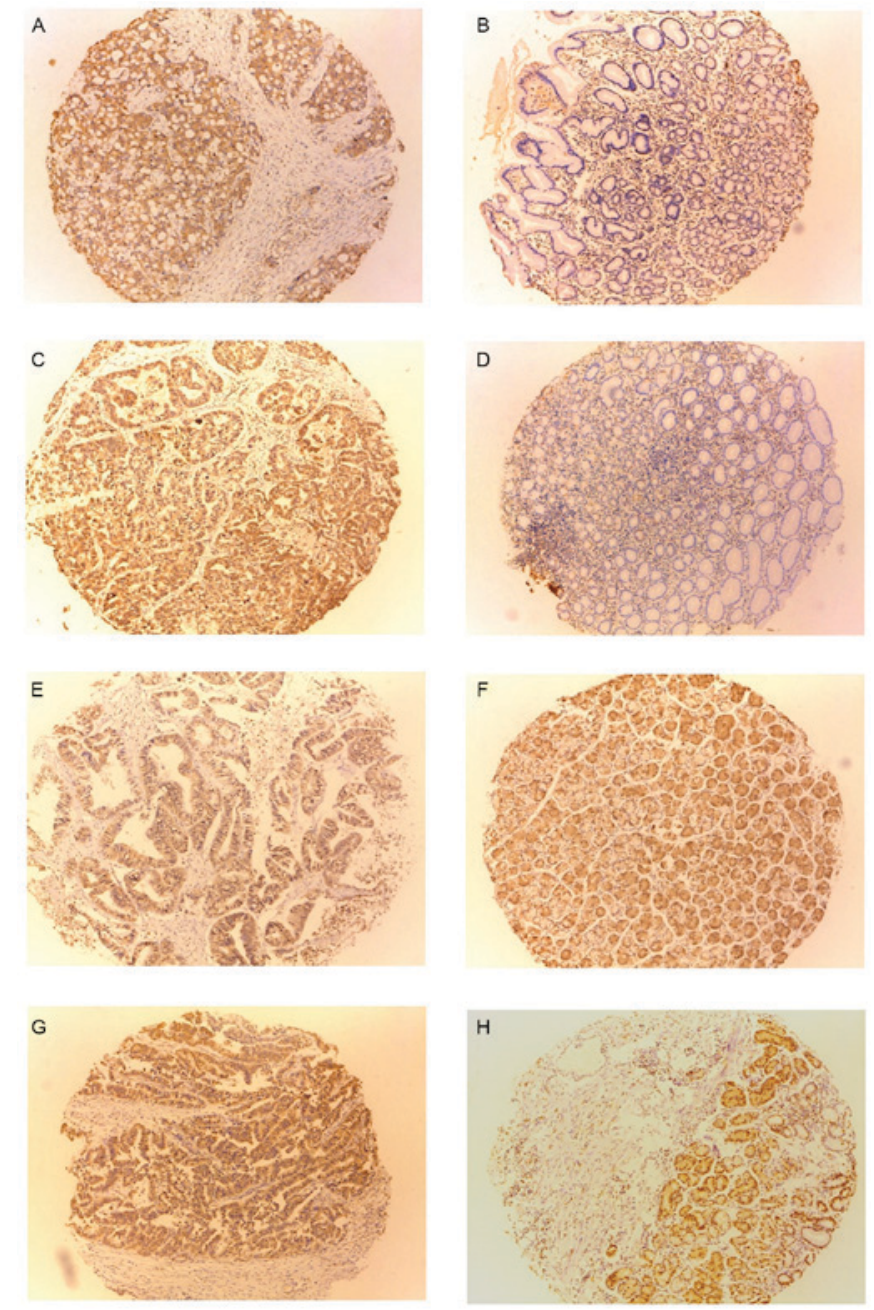

Figure 1. Representative illustrations of the immunohistochemistry analysis of c-Met, PI3K, Beclin-1 and CagA in normal gastric mucosae and GC tissues (magnification, $\mathrm{x} 40$ ). (A) c-Met expression in normal gastric mucosae. (B) c-Met expression in GC tissue. (C) PI3K expression in normal gastric mucosae. (D) PI3K expression in GC tissue. (E) Beclin-1 expression in normal gastric mucosae. (F) Beclin-1 expression in GC tissue. (G) CagA expression in normal gastric mucosae. $(\mathrm{H}) \mathrm{CagA}$ expression in $\mathrm{GC}$ tissue. PI3K, phosphatidylinositol-4,5-bisphosphate 3-kinase; CagA, cytotoxin-associated gene A; GC, gastric cancer.

$(2+, 29 ; 1+, 22)$, the expression of Beclin-1 was detected in a low proportion of GC samples $(53 / 121,43.8 \%$; $\mathrm{P}=0.001)$. A total of 23 cases in GC exhibited a high level of Beclin-1 expression $(4+, 9 ; 3+, 14)$ and low expression was exhibited in 30 cases $(2+, 17 ; 1+, 13$; Table I; Fig. 1E and F). 
Table II. Association between the characteristics of patients with gastric cancer and the expression of c-Met, PI3K, Beclin-1 and CagA.

\begin{tabular}{|c|c|c|c|c|c|c|c|c|c|}
\hline \multirow{2}{*}{$\begin{array}{l}\text { Clinicopathological } \\
\text { factor }\end{array}$} & \multirow[b]{2}{*}{ Cases, n (\%) } & \multicolumn{2}{|c|}{ c-Met } & \multicolumn{2}{|c|}{ PI3K } & \multicolumn{2}{|c|}{ Beclin-1 } & \multicolumn{2}{|c|}{ CagA } \\
\hline & & $\mathrm{n}(\%)$ & P-value & $\mathrm{n}(\%)$ & P-value ${ }^{a}$ & $\mathrm{n}(\%)$ & P-value ${ }^{a}$ & $\mathrm{n}(\%)$ & P-value ${ }^{a}$ \\
\hline \multicolumn{10}{|l|}{ Sex } \\
\hline Male & $71(58.7)$ & $52(73.2)$ & 0.167 & $55(77.5)$ & 0.401 & $30(42.3)$ & 0.713 & $51(71.8)$ & 0.841 \\
\hline Female & $50(41.3)$ & $30(60.0)$ & & $35(70.0)$ & & $23(46.0)$ & & $35(70.0)$ & \\
\hline \multicolumn{10}{|l|}{ Age } \\
\hline$<56$ years & $56(46.3)$ & $36(64.3)$ & 0.559 & $39(69.6)$ & 0.301 & $27(48.2)$ & 0.463 & $38(67.9)$ & 0.548 \\
\hline$\geq 56$ years & $65(53.7)$ & $46(70.8)$ & & $51(78.5)$ & & $26(40.0)$ & & $48(73.8)$ & \\
\hline \multicolumn{10}{|l|}{ Tumor size } \\
\hline$<5 \mathrm{~cm}$ & $60(49.6)$ & $36(60.0)$ & 0.082 & $43(71.7)$ & 0.537 & $27(45.0)$ & 0.855 & $42(70.0)$ & 0.843 \\
\hline$\geq 5 \mathrm{~cm}$ & $61(50.4)$ & $46(75.4)$ & & $47(77.0)$ & & $26(42.6)$ & & $44(72.1)$ & \\
\hline \multicolumn{10}{|l|}{ Depth of invasion } \\
\hline Uninvolved serosa & $35(28.9)$ & $21(60.0)$ & 0.286 & $21(60.0)$ & 0.037 & $17(48.6)$ & 0.548 & $18(51.4)$ & 0.004 \\
\hline Serosal invasion & $86(71.1)$ & $61(70.9)$ & & $69(80.2)$ & & $36(41.9)$ & & $68(79.1)$ & \\
\hline \multicolumn{10}{|l|}{ Differentiation } \\
\hline Well or moderate & $100(82.6)$ & $65(65.0)$ & 0.203 & $72(72.0)$ & 0.237 & $49(49.0)$ & 0.015 & $72(72.0)$ & 0.607 \\
\hline Poor & $21(17.4)$ & $17(81.0)$ & & $18(85.7)$ & & $4(19.0)$ & & 14 (66.7) & \\
\hline \multicolumn{10}{|l|}{$\begin{array}{l}\text { Lymph node } \\
\text { invasion status }\end{array}$} \\
\hline Negative & $66(54.5)$ & 38 (57.6) & 0.011 & $41(62.1)$ & 0.001 & $35(53.0)$ & 0.029 & $36(54.5)$ & $<0.001$ \\
\hline Positive & $55(45.5)$ & $44(80.0)$ & & $49(89.1)$ & & $18(32.7)$ & & $50(90.9)$ & \\
\hline \multicolumn{10}{|l|}{ TNM stage } \\
\hline I or II & $63(52.1)$ & $36(57.1)$ & 0.011 & $38(60.3)$ & $<0.001$ & $34(54.0)$ & 0.027 & 34 (53.9) & $<0.001$ \\
\hline III or IV & $58(47.9)$ & $46(79.3)$ & & $52(89.7)$ & & $19(32.8)$ & & $52(89.7)$ & \\
\hline
\end{tabular}

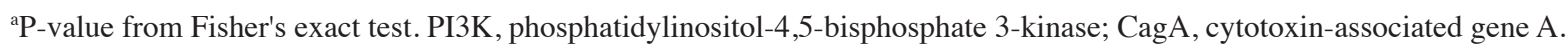

CagA expression was significantly more likely in GC tissue, as 86 of the $121 \mathrm{GC}$ tissue samples (71.1\%) exhibited positive CagA expression, including 27 with high expression $(4+, 9 ; 3+, 18)$ and 59 with low expression $(2+, 30 ; 1+, 29)$, whereas 54 normal gastric mucosa tissue samples exhibited positive expression, including 27 with high expression $(4+, 10$; $3+, 17)$ and 27 with low expression $(2+, 19 ; 1+, 8 ; 45 \% ; \mathrm{P}<0.001$; Table I; Fig. 1G and $\mathrm{H}$ ).

Clinicopathological significance of c-Met/PI3K/Beclin-1/ CagA expression. The associations between the levels of c-Met, PI3K, Beclin-1 and CagA expression and clinicopathological characteristics are reported in Table II. The high expression of c-Met was associated with lymphatic metastasis $(\mathrm{P}=0.011)$ and the TNM stage of $\mathrm{GC}(\mathrm{P}=0.011)$. High levels of CagA and PI3K were associated with the depth of tumor invasion $(\mathrm{P}=0.004$ and $\mathrm{P}=0.037$, respectively), lymphatic metastasis $(\mathrm{P}<0.001$ and $\mathrm{P}=0.001$, respectively) and the TNM stage (both $\mathrm{P}<0.001)$. Low Beclin-1 expression was associated with the degree of differentiation $(\mathrm{P}=0.015)$, lymph node metastasis $(\mathrm{P}=0.029)$ and the TNM stage $(\mathrm{P}=0.027)$. The data may indicate that c-Met, PI3K and Beclin-1 expression, and CagA-positive $H$. pylori infection are all involved in the molecular mechanisms for the progression of GC.
Association between CagA, c-Met, PI3K and Beclin-1 expression. As included in Table III, the data suggested an association between CagA and c-Met or Beclin-1 expression in $121 \mathrm{GC}$ tissue samples. There were $64 \mathrm{c}-\mathrm{Met} / \mathrm{CagA}$-positive and $17 \mathrm{c}-\mathrm{Met} / \mathrm{CagA}$-negative tumors $\left(\mathrm{R}_{\mathrm{s}}=0.223, \mathrm{P}=0.014\right)$, and 32 Beclin-1/CagA-positive and 14 Beclin-1/CagA-negative tumors $\left(\mathrm{R}_{\mathrm{s}}=-0.245, \mathrm{P}=0.007\right)$. No significant correlation between PI3K and CagA positivity was identified $\left(\mathrm{R}_{\mathrm{s}}=0.127\right.$, $\mathrm{P}=0.164)$. In all 121 gastric cancer patients, 86 patients had high expression of CagA (positive rate, 71.1\%). In the CagA-positive group, 32 patients had low expression of Beclin-1 (32/86; 37.2\%; $\mathrm{P}=0.007)$ and 64 patients had high levels of c-Met $(\mathrm{P}=0.014)$. However, $\mathrm{CagA}$ was not associated with high expression of PI3K ( $\mathrm{P}=0.164)$ (Table III).

c-Met, PI3K, Beclin-1 and CagA expression association with patient survival. The association between c-Met, PI3K, Beclin-1 and CagA expression and the survival rate of patients with GC was assessed (Table IV; Fig. 2). The high expression of c-Met and CagA in tissues were significantly associated with poor DFS rate $(\log$-rank $\mathrm{P}=0.010$ and $\mathrm{P}=0.020$, respectively; Fig. $2 \mathrm{~A}$ and $\mathrm{B}$ ). Furthermore, the high expression of c-Met and PI3K were significantly associated with a poor OS rate $(\log$-rank $\mathrm{P}=0.003$ and $\mathrm{P}=0.035$, 
Table III. Correlation between CagA expression with the expression of c-Met, PI3K and Beclin-1.

\begin{tabular}{|c|c|c|c|c|c|c|c|c|c|c|c|c|}
\hline \multirow[b]{2}{*}{ CagA } & \multicolumn{2}{|c|}{ c-Met } & \multirow[b]{2}{*}{$\mathrm{R}_{\mathrm{s}}$} & \multirow[b]{2}{*}{ P-value } & \multicolumn{2}{|c|}{ PI3K } & \multirow[b]{2}{*}{$\mathrm{R}_{\mathrm{s}}$} & \multirow[b]{2}{*}{ P-value } & \multicolumn{2}{|c|}{ Beclin-1 } & \multirow[b]{2}{*}{$\mathrm{R}_{\mathrm{s}}$} & \multirow[b]{2}{*}{$\mathrm{P}$-value } \\
\hline & - & + & & & - & + & & & - & + & & \\
\hline Negative & 17 & 18 & 0.223 & 0.014 & 12 & 23 & 0.127 & 0.164 & 14 & 21 & -0.245 & 0.007 \\
\hline Positive & 22 & 64 & & & 19 & 67 & & & 54 & 32 & & \\
\hline Total & 39 & 82 & & & 31 & 90 & & & 68 & 53 & & \\
\hline
\end{tabular}

CagA, cytotoxin-associated gene A; PI3K, phosphatidylinositol-4,5-bisphosphate 3-kinase; $\mathrm{R}_{\mathrm{s}}$, Spearman's correlation coefficient.

Table IV. Univariate analysis of the association between 5-year DFS and OS and clinicopathological factors, including the expression of c-Met, PI3K and Beclin-1.

\begin{tabular}{|c|c|c|c|c|c|}
\hline \multirow[b]{2}{*}{ Clinicopathological factors } & \multirow[b]{2}{*}{ Cases, $\mathrm{n}$} & \multicolumn{2}{|c|}{ 5-year DFS } & \multicolumn{2}{|c|}{ 5-year OS } \\
\hline & & $\mathrm{n}(\%)$ & P-value & $\mathrm{n}(\%)$ & P-value \\
\hline \multicolumn{6}{|l|}{ Sex } \\
\hline Male & 71 & $40(56.3)$ & \multirow[t]{2}{*}{0.321} & $39(54.9)$ & \multirow[t]{2}{*}{0.488} \\
\hline Female & 50 & $33(66.0)$ & & $31(62.0)$ & \\
\hline \multicolumn{6}{|l|}{ Age } \\
\hline$<56$ years & 56 & $38(67.9)$ & \multirow[t]{2}{*}{0.101} & $39(69.6)$ & \multirow[t]{2}{*}{0.017} \\
\hline$\geq 56$ years & 65 & $35(53.8)$ & & $31(47.7)$ & \\
\hline \multicolumn{6}{|l|}{ Tumor size } \\
\hline$<5 \mathrm{~cm}$ & 60 & $43(71.7)$ & \multirow[t]{2}{*}{0.009} & $43(71.7)$ & \multirow[t]{2}{*}{0.002} \\
\hline$\geq 5 \mathrm{~cm}$ & 61 & $30(49.2)$ & & $27(44.3)$ & \\
\hline \multicolumn{6}{|l|}{ Depth of invasion } \\
\hline Uninvolved serosa & 35 & $25(71.4)$ & \multirow[t]{2}{*}{0.120} & $24(68.6)$ & \multirow[t]{2}{*}{0.095} \\
\hline Serosal invasion & 86 & $48(55.8)$ & & $46(53.5)$ & \\
\hline \multicolumn{6}{|l|}{ Differentiation } \\
\hline Well or moderate & 100 & $66(66.0)$ & \multirow[t]{2}{*}{0.003} & $64(64.0)$ & \multirow[t]{2}{*}{0.001} \\
\hline Poor & 21 & $7(33.3)$ & & $6(28.6)$ & \\
\hline \multicolumn{6}{|l|}{ Lymph node invasion status } \\
\hline Negative & 66 & $47(71.2)$ & \multirow[t]{2}{*}{0.005} & $49(74.2)$ & \multirow[t]{2}{*}{$<0.001$} \\
\hline Positive & 55 & $26(47.3)$ & & $21(38.2)$ & \\
\hline \multicolumn{6}{|l|}{ TNM stage } \\
\hline I or II & 63 & $47(74.6)$ & \multirow[t]{2}{*}{$<0.001$} & $49(77.8)$ & \multirow[t]{2}{*}{$<0.001$} \\
\hline III or IV & 58 & $26(44.8)$ & & $21(36.2)$ & \\
\hline \multicolumn{6}{|l|}{ c-Met } \\
\hline Negative & 39 & $30(76.9)$ & \multirow[t]{2}{*}{0.010} & $31(79.5)$ & \multirow[t]{2}{*}{0.003} \\
\hline Positive & 82 & $43(52.4)$ & & 39 (47.6) & \\
\hline \multicolumn{6}{|l|}{ PI3K } \\
\hline Negative & 31 & $22(70.9)$ & 0.152 & $22(70.9)$ & 0.035 \\
\hline Positive & 90 & $51(56.7)$ & & $48(53.3)$ & \\
\hline Beclin-1 & & & & & \\
\hline Negative & 68 & $31(45.6)$ & $<0.001$ & $30(44.1)$ & 0.001 \\
\hline Positive & 53 & $42(79.2)$ & & $40(75.5)$ & \\
\hline CagA & & & & & \\
\hline Negative & 35 & $27(77.1)$ & 0.020 & $25(71.4)$ & 0.072 \\
\hline Positive & 86 & $46(53.5)$ & & $45(52.3)$ & \\
\hline
\end{tabular}

aP-value from a univariate two-sided log-rank test. DFS, disease-free survival; OS, overall survival; PI3K, phosphatidylinositol-4,5-bisphosphate 3-kinase; CagA, cytotoxin-associated gene A. 
A

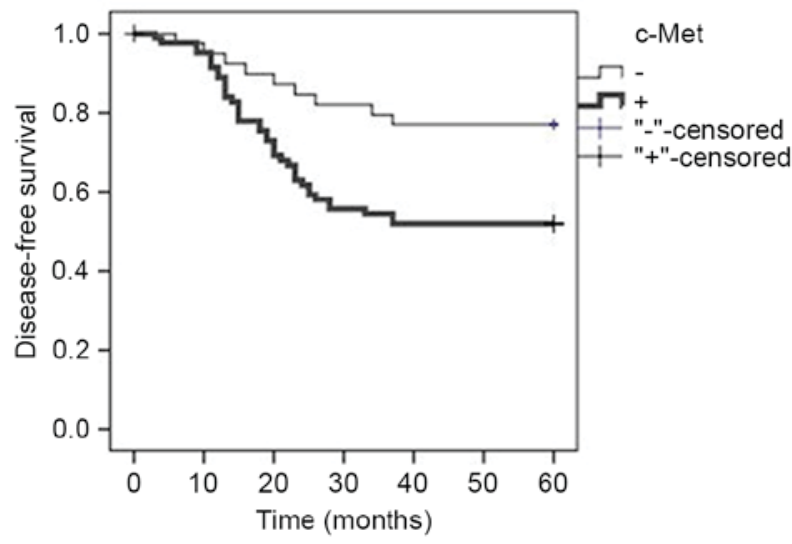

C

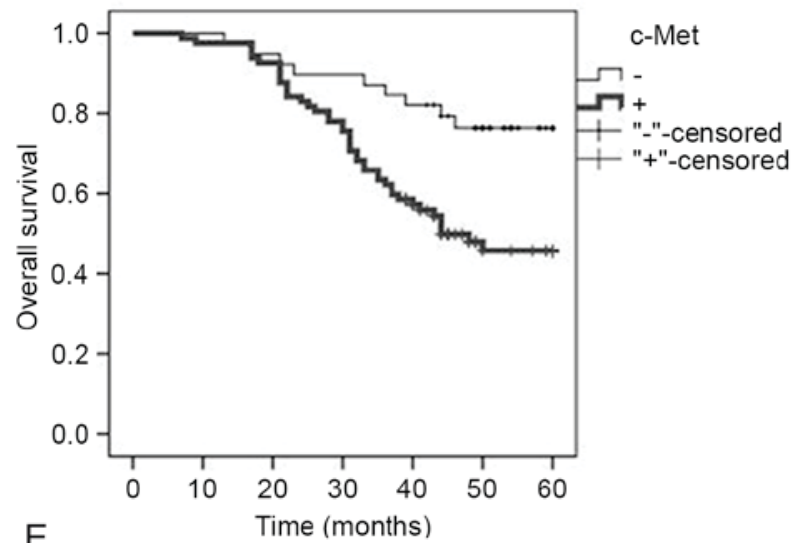

$\mathrm{E}$

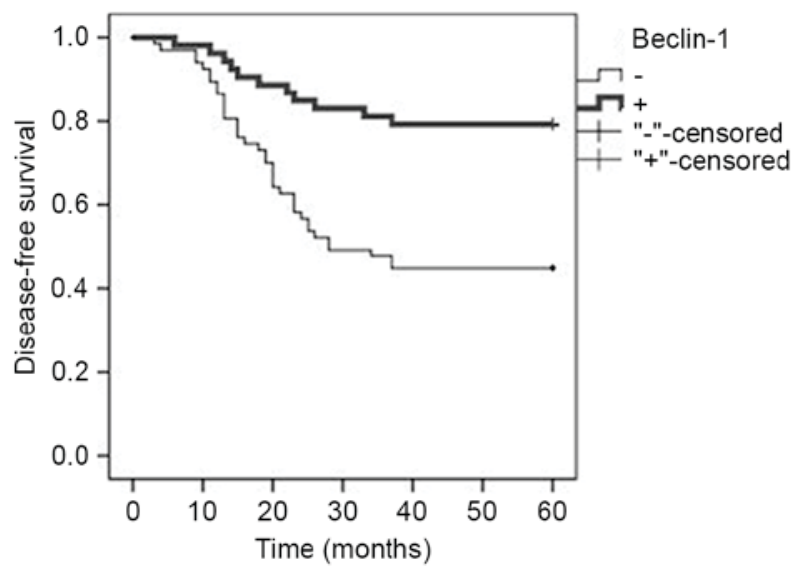

B

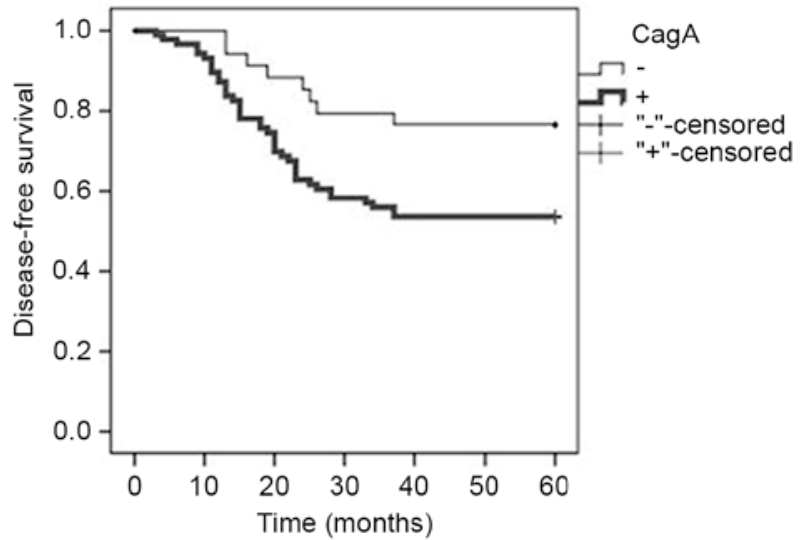

D
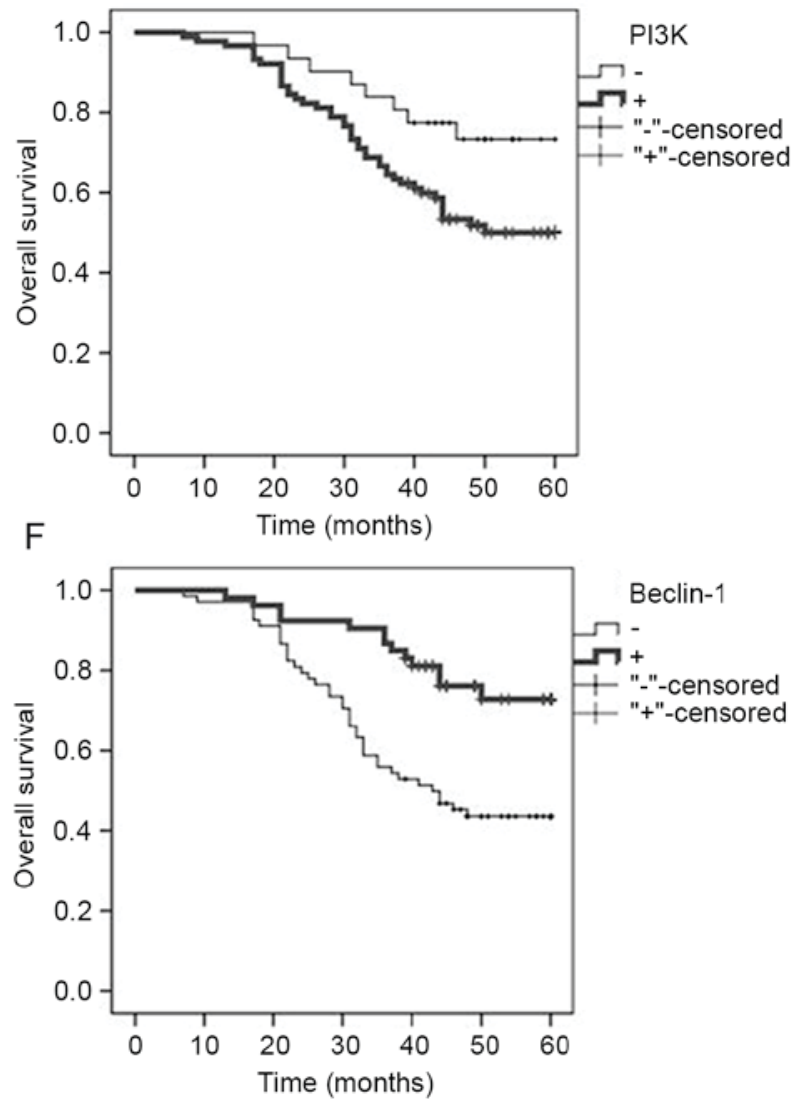

Figure 2. Kaplan-Meier survival curves for the DFS and OS of 121 patients with GC according to the expression status of c-Met, PI3K, Beclin-1 and CagA. The log-rank test was used to determine the significance of associations between survival and expression. (A) The expression of c-Met in GC tissue was associated with a poor DFS rate $(\mathrm{P}=0.010)$. (B) The expression of CagA in $\mathrm{GC}$ tissue was associated with a poor $\mathrm{DFS}$ rate $(\mathrm{P}=0.020)$. (C) The expression of c-Met in GC tissue was associated with a poor OS rate (P=0.003). (D) The expression of PI3K in GC tissue was associated with a poor OS rate (P=0.035). (E) The negative expression of Beclin-1 in GC tissue was associated with a poor DFS rate $(\mathrm{P}<0.001)$. (F) The negative expression of Beclin-1 in GC tissue was associated with a poor OS rate $(\mathrm{P}=0.001)$. DFS, disease-free survival; OS, overall survival; $\mathrm{GC}$, gastric cancer; PI3K, phosphatidylinositol-4,5-bisphosphate 3-kinase; CagA, cytotoxin-associated gene A.

respectively; Fig. 2C and D). Low expression of Beclin-1 was also significantly associated with a poor DFS and OS rate (log-rank $\mathrm{P}<0.001$ and $\mathrm{P}=0.001$, respectively; Fig. $2 \mathrm{E}$ and $\mathrm{F}$ ). However, the expression of PI3K was not significantly associated with the DFS rate (log-rank $\mathrm{P}=0.152$; data not shown) and CagA was not associated with the OS rate (log-rank $\mathrm{P}=0.072$; data not shown).

In a univariate analysis, the high expression of c-Met (HR, 2.502; 95\% CI, 1.211-5.171; $\mathrm{P}=0.013$ ) or CagA (HR, 2.384;
95\% CI, 1.115-5.095; $\mathrm{P}=0.025)$ were associated with a poor DFS rate. In addition, the high expression of c-Met (HR, 2.825; 95\% CI, 1.371-5.820; $\mathrm{P}=0.005)$ or PI3K (HR, 2.193; 95\% CI, 1.030-4.666; $\mathrm{P}=0.042$ ) were associated with a poor OS rate. The low expression of Beclin-1 was also significantly associated with a poor DFS (HR, 0.296; 95\% CI, 0.151-0.581; $\mathrm{P}<0.001)$ and $\mathrm{OS}$ rate $(\mathrm{HR}, 0.35 ; 95 \% \mathrm{CI}, 0.186-0.658$; $\mathrm{P}=0.001)$. However, the high expression of $\mathrm{PI} 3 \mathrm{~K}$ was not significantly associated with the DFS rate $(\mathrm{P}=0.16)$ and the 
Table V. Univariate and multivariate analysis of the association between DFS and OS and clinicopathological factors, including the expression of c-Met, PI3K, Beclin-1 and CagA.

A, Association with 5-year DFS

\begin{tabular}{lccccc}
\hline & \multicolumn{2}{c}{ Univariate analysis } & & \multicolumn{2}{c}{ Multivariate analysis } \\
\cline { 2 - 3 } Variable & P-value & HR $(95 \%$ CI $)$ & & P-value & HR (95\% CI) \\
\hline Sex (male/female) & 0.298 & $0.730(0.404-1.320)$ & & - & - \\
Age $(\geq 56 /<56$ years) & 0.124 & $1.583(0.882-2.840)$ & & - & - \\
Tumor size $(\geq 5 /<5$ cm) & 0.013 & $2.117(1.170-3.829)$ & & 0.014 & $2.108(1.163-3.820)$ \\
Serosal invasion status & 0.117 & $1.745(0.870-3.503)$ & & - & - \\
Differentiation (moderate and well/poor) & 0.002 & $2.659(1.424-4.966)$ & & - & - \\
Lymph node invasion status & 0.008 & $2.199(1.232-3.928)$ & & 0.031 & $1.725(0.954-2.541)$ \\
TNM stage (I and II/III and IV) & 0.001 & $2.759(1.511-5.037)$ & & 0.002 & $2.423(1.159-4.152)$ \\
c-Met expression status & 0.013 & $2.502(1.211-5.171)$ & & 0.049 & $2.083(1.004-4.322)$ \\
PI3K expression status & 0.016 & $1.681(0.814-3.472)$ & & - & - \\
Beclin-1 expression status & $<0.001$ & $0.296(0.151-0.581)$ & & 0.001 & $0.312(0.158-0.616)$ \\
CagA expression status & 0.025 & $2.384(1.115-5.095)$ & & - & - \\
\hline
\end{tabular}

B, Association with 5-year OS

\begin{tabular}{|c|c|c|c|c|}
\hline \multirow[b]{2}{*}{ Variable } & \multicolumn{2}{|c|}{ Univariate analysis } & \multicolumn{2}{|c|}{ Multivariate analysis } \\
\hline & P-value & $\operatorname{HR}(95 \% \mathrm{CI})$ & P-value & $\mathrm{HR}(95 \% \mathrm{CI})$ \\
\hline Sex (male/female) & 0.492 & $0.819(0.464-1.446)$ & - & - \\
\hline Age $(\geq 56 /<56$ years $)$ & 0.020 & $2.001(1.116-3.586)$ & 0.020 & $2.018(1.119-3.642)$ \\
\hline Tumor size $(\geq 5 /<5 \mathrm{~cm})$ & 0.003 & $2.445(1.363-4.389)$ & 0.015 & $2.121(1.160-3.879)$ \\
\hline Serosal invasion status & 0.102 & $1.746(0.895-3.406)$ & - & - \\
\hline Differentiation (moderate and well/poor) & 0.002 & $2.595(1.419-4.747)$ & 0.022 & $0.740(1.123-3.828)$ \\
\hline Lymph node invasion status & $<0.001$ & $3.062(1.708-5.491)$ & 0.015 & $0.217(0.064-0.742)$ \\
\hline TNM stage (I and II/III and IV) & $<0.001$ & $3.898(2.102-7.226)$ & $<0.001$ & $13.580(3.739-49.330)$ \\
\hline c-Met expression status & 0.005 & $2.825(1.371-5.820)$ & - & - \\
\hline PI3K expression status & 0.042 & $2.193(1.030-4.666)$ & - & - \\
\hline Beclin-1 expression status & 0.001 & $0.350(0.186-0.658)$ & - & - \\
\hline CagA expression status & 0.079 & $0.857(0.930-3.710)$ & - & - \\
\hline
\end{tabular}

DFS, disease-free survival; OS, overall survival; PI3K, phosphatidylinositol-4,5-bisphosphate 3-kinase; CagA, cytotoxin-associated gene A; HR, hazard ratio; CI, confidence interval.

expression of CagA was not significantly associated with the OS rate $(\mathrm{P}=0.079$; Table $\mathrm{V})$.

In multivariate analysis of Table $\mathrm{V}$, the high expression of c-Met and low expression of Beclin-1 were associated with a poor DFS rate (adjusted HR, 2.083; 95\% CI, 1.004-4.322; $\mathrm{P}=0.049$; adjusted HR, 0.312; 95\% CI, 0.158-0.616; $\mathrm{P}=0.001$, respectively).

\section{Discussion}

Cancer is a considerable burden on global health. Within the next twenty years, new cancer cases and mortalities worldwide annually will reach 22 million and 13 million, respectively (1). $\mathrm{GC}$ is the second most common cause for cancer-associated mortality (2). An estimated $20-25 \%$ of all cases of cancer worldwide are associated with inflammation induced by microbial infection (24). CagA-positive H. pylori infection is a severe risk factor for the initiation and development of human GC (17). In the present study, the CagA-positive rate in GC tissues was determined to be significantly higher than in normal tissues. The expression of CagA was significantly associated with the depth of tumor invasion, lymph node metastasis and the TNM tumor stage of GC. Tumor CagA-positivity was negatively associated with the likelihood of 5-year DFS. CagA is implicated in the neoplasia, invasion and metastasis of GC (10-12). Thus, it was demonstrated that the eradication of CagA-positive $H$. pylori infection may reduce the rate of GC incidence, and may also prolong the DFS period of patients with GC.

c-Met protein is a transmembrane protein derived from a $170-\mathrm{kDa}$ precursor (25). c-Met function is normally associated 
with embryonic development and damage repair; however, deregulation of the protein induces tumorigenesis (26). Churin et al (17) demonstrated that H. pylori CagA protein targets the c-Met receptor to invoke a mitogenic response. Yang et al (12) verified that interactions between genes affected by CagA and c-Met significantly intensified the risk of GC. In solid tumors, aberrant c-Met phosphorylation can facilitate the epithelial-mesenchymal transition, a key step in tumor progression to metastatic disease $(20,22,24)$. Churin et al (17) demonstrated that CagA interacts with c-Met in cells co-cultured with $H$. pylori. Oliveira et al also suggest that $H$. pylori-induced cell invasion requires c-Met activity (27). These reports revealed that $H$. pylori may not only have a role in gastric carcinogenesis, but also in the progression of the tumor to invasion and metastasis through the CagA-dependent activation of the c-Met receptor $(17,27,28)$. The data of the present study demonstrated that the expression of c-Met was higher in GC tissue than in normal gastric mucosa. The expression of c-Met was significantly associated with lymphatic metastasis and the TNM stage of GC. The expression of c-Met was significantly negatively associated with the likelihood of 5-year DFS and OS. There was additionally a statistically significant association between c-Met- and CagA-positivity. This result indicates that CagA-positive H. pylori infection was associated with the c-Met-dependent signaling pathway in $\mathrm{GC}$ genesis, progression and metastasis.

$H$. pylori infection stimulates c-Met phosphorylation via interaction with CagA, which promotes $H$. pylori-induced cancer cell motility and invasion. The interaction of c-Met with Cag A may lead to PI3K activation. Activated PI3K stimulates the phosphorylation of Akt. The phosphorylation of Akt promotes tumor cell invasion and the expression of oncogenes through the PI3K/Akt signaling pathway. The activated Akt stimulates the phosphorylation of downstream target proteins, suppresses autophagy and increases the resistance to apoptosis. These events promote gastric tumor cell proliferation and invasion (19-22,29). The results of the present study demonstrated that the expression of PI3K was higher in GC tissues than in normal gastric mucosa. The expression of PI3K was significantly associated with the depth of tumor invasion, lymphatic metastasis and TNM tumor stage of GC. The expression of PI3K was significantly negatively associated with the likelihood of 5-year OS. There was no observed association between PI3K and CagA-positivity, although this association may be observable in a larger study cohort. The expression of Beclin-1 was significantly lower in GC tissue, particularly in CagA-positive GC cases. The data have demonstrated that Cag A-positive H. pylori infection was associated with the suppression of autophagy in the neoplasia and metastasis of GC. Once the underlying oncogenic mechanisms have been confirmed, it may be possible to classify tumors and develop targeted therapies for individual tumors. An additional study with a larger sample size will be performed in the near future.

To conclude, the findings of the present study indicate that CagA-positive $H$. pylori infection, and the expression of c-Met, PI3K and Beclin-1 may have major roles in the oncogenesis, invasive growth and lymph node metastasis of GC. The DFS rate was significantly negatively associated with the expression of c-Met and CagA in GC tissue whereas it was positively associated with
Beclin-1 expression. OS was also negatively associated with expression of c-Met and PI3K, whereas it was positively associated with Beclin-1. Furthermore, c-Met and Beclin-1 could be an independent and efficient biomarker for predicting the DFS of GC patients. In CagA-positive H. pylori infection-associated GC, c-Met expression was upregulated, and Beclin-1 expression was downregulated, significantly. Cag A-positive $H$. pylori infection was closely associated with the c-Met-dependent signaling pathway and the suppression of autophagy in the neoplasia, invasion and metastasis of GC. The investigation indicated that modulators targeting c-Met or promoting Beclin-1 may be suitable for development as agents for treating GC, particularly CagA-positive H. pylori infection-associated GC.

\section{References}

1. Stewart BW and Wild CP: World Cancer Report 2014. Geneva: World Health Organization, International Agency for Research on Cancer, WHO Press, 2015.

2. Zhang S, Chen P, Huang Z, Hu X, Chen M, Hu S, Hu Y and Cai T: Sirt7 promotes gastric cancer growth and inhibits apoptosis by epigenetically inhibiting miR-34a. Sci Rep 10: 9787, 2015.

3. WHO. A Survey of Cancer, 2014 [DB/OL]. http://www.who int/cancer/country-profiles/en/, 2014.

4. Siegel R, Naishadham D and Jemal A: Cancer statistics for Hispanics/Latinos. CA Cancer J Clin 62: 283-298, 2012.

5. Li ZX and Kaminishi MA: Comparison of gastric cancer between Japan and China. Gastric Cancer 12: 52-53, 2009.

6. International Agency for Research on Cancer. Helicobatcer pylori Eradication as a Strategy for Preventing Gastric Cancer, IARC Working Group Reports. Vol 8, Lyon: IARC, 2013. Available from: http://www.iarc.fr/en/publications/pdfs-online/wrk/wrk8/Helicobacter_pylori_Eradication.pdf. Accessed June 14, 2016.

7. Odenbreit S, Püls J, Sedlmaier B, Gerland E, Fischer W and Haas R: Translocation of Helicobacter pylori CagA into gastric epithelial cells by type IV secretion. Science 287: 1497-1500, 2000.

8. Higashi H, Tsutsumi R, Muto S, Sugiyama T, Azuma T, Asaka M and Hatakeyama M: SHP-2 tyrosine phosphatase as an intracellular target of Helicobacter pylori CagA protein. Science 295: 683-686, 2002.

9. Higashi H, Yokoyama K, Fujii Y, Ren S, Yuasa H, Saadat I, Murata-Kamiya N, Azuma T and Hatakeyama M: EPIYA motif is a membrane-targeting signal of Helicobacter pylori virulence factor CagA in mammalian cells. J Biol Chem 280: 23130-23137, 2005.

10. Peek RM Jr and Blaser MJ: Helicobacter pylori and gastrointestinal tract adenocarcinomas. Nat Rev Cancer 2: 28-37, 2002.

11. Blaser MJ, Perez-Perez GI, Kleanthous H, Cover TL, Peek RM, Chyou PH, Stemmermann GN and Nomura A: Infection with Helicobacter pylori strains possessing cagA is associated with an increased risk of developing adenocarcinoma of the stomach. Cancer Res 55: 2111-2115, 1995.

12. Yang JJ, Yang JH, Kim J, Ma SH, Cho LY, Ko KP, Shin A, Choi BY, Kim HJ, Han DS, et al: Soluble c-Met protein as a susceptible biomarker for gastric cancer risk: A nested case-control study within the Korean Multicenter Cancer Cohort. Int J Cancer 132: 2148-2156, 2013.

13. Taniguchi K, Yonemura Y, Nojima N, Hirono Y, Fushida S, Fujimura T, Miwa K, Endo Y, Yamamoto H and Watanabe H: The relation between the growth patterns of gastric carcinoma and the expression of hepatocyte growth factor receptor (c-met), autocrine motility factor receptor, and urokinase-type plasminogen activator receptor. Cancer 82: 2112-2122, 1998.

14. Toiyama Y, Yasuda H, Saigusa S, Matushita K, Fujikawa H, Tanaka K, Mohri Y, Inoue Y, Goel A and Kusunoki M: Co-expression of hepatocyte growth factor and c-Met predicts peritoneal dissemination established by autocrine hepatocyte grow th factor/c-Met signaling in gastric cancer. Int J Cancer 130: 2912-2921, 2012.

15. Li Y, Chen CQ, He YL, Cai SR, Yang DJ, He WL, Xu JB and Zan WH: Abnormal expression of E-cadherin in tumor cells is associated with poor prognosis of gastric carcinoma. J Surg Oncol 106: 304-310,2012. 
16. Yildız Y, Sokmensuer C and Yalcin S: Evaluation of c-Met, HGF, and HER-2 expressions in gastric carcinoma and their association with other clinicopathological factors. Onco Targets Ther 9: 5809-5817, 2016

17. Churin Y, Al-Ghoul L, Kepp O, Meyer TF, Birchmeier W and Naumann M: Helicobacter pylori CagA protein targets the c-Met receptor and enhances the motogenic response. J Cell Biol 161: 249-255, 2003

18. Wang RC, Wei Y, An Z, Zou Z, Xiao G, Bhagat G, White M, Reichelt $\mathrm{J}$ and Levine B: Akt-mediated regulation of autophagy and tumorigenesis through Beclin 1 phosphorylation. Science 338: 956-959, 2012.

19. Vasconcelos AC, Wagner VP, Meurer L, Vargas PA, de Souza LB Fonseca FP, Squarize CH, Castilho RM and Martins MD: Immunoprofile of c-MET/PI3K signaling in human salivary gland tumors. Oral Surg Oral Med Oral Pathol Oral Radiol 120: 238-247, 2015.

20. Zhuo B, Li Y, Li Z, Qin H, Sun Q, Zhang F, Shen Y, Shi Y and Wang R: PI3K/Akt signaling mediated Hexokinase-2 expression inhibits cell apoptosis and promotes tumor growth in pediatric osteosarcoma. Biochem Biophys Res Commun 464: 401-406, 2015.

21. Jung KA, Choi BH and Kwak MK: The c-MET/PI3K signaling is associated with cancer resistance to doxorubicin and photodynamic therapy by elevating BCRP/ABCG2 expression. Mol Pharmacol 87: 465-476, 2015.

22. Wu J, Chen $\mathrm{C}$ and Zhao KN: Phosphatidylinositol 3-kinase signaling as a therapeutic target for cervical cancer. Curr Cancer Drug Targets 13: 143-156, 2013.

23. Edge SB, Byrd DR, Compton CC, Fritz AG, Greene FL and Trotti A: AJCC Cancer Staging Manual. 7th edition. Springer, New York, pp191-200, 2010.
24. Okada F: Inflammation-related carcinogenesis: Current findings in epidemiological trends, causes and mechanisms. Yonago Acta Med 57: 65-72, 2014.

25. Wajih N, Walter J and Sane DC: Vascular origin of a soluble truncated form of the hepatocyte growth factor receptor (c-met). Circ Res 90: 46-52, 2002.

26. Porter J: Small molecule c-Met kinase inhibitors: A review of recent patents. Expert Opin Ther Pat 20: 159-177, 2010.

27. Oliveira MJ, Costa AC, Costa AM, Henriques L, Suriano G, Atherton JC, Machado JC, Carneiro F, Seruca R, Mareel M, et al: Helicobacter pylori induces gastric epithelial cell invasion in a c-Met and type IV secretion system-dependent manner. J Biol Chem 281: 34888-34896, 2006.

28. Snider JL and Cardelli JA: Helicobacter pylori induces cancer cell motility independent of the c-Met receptor. J Carcinog 8: 7 , 2009.

29. Hu Y, Li L, Yin W, Shen L, You B and Gao H: Protective effect of proanthocyanidins on anoxia-reoxygenation injury of myocardial cells mediated by the PI3K/Akt/GSK-3 $\beta$ pathway and mitochondrial ATP-sensitive potassium channel. Mol Med Rep 10: 2051-2058, 2014.

(i) (2) This work is licensed under a Creative Commons Attribution-NonCommercial-NoDerivatives 4.0 International (CC BY-NC-ND 4.0) License. 